10.1590/S1414-40772018000300001

Este é um artigo publicado em acesso aberto sob uma licença Creative Commons

https://creativecommons.org/licenses/by-nc/4.0/

\title{
Editorial
}

\section{Responsabilidade social da Universidade em questão}

\author{
José Dias Sobrinho ${ }^{1}$ \\ ${ }^{1}$ Pesquisador autônomo, \\ Universidade Estadual de Campinas \\ Campinas, São Paulo, Brasil
}

Responsabilidade social da Universidade, quem é contra? Todos apregoam que a Universidade tem uma enorme responsabilidade social. Mas de que se fala quando se fala de responsabilidade social? Há um mínimo de consenso acerca de seus significados? Ou não passam de palavras sem aderência à realidade? Como tudo que é social e de interesse da sociedade, também os conceitos de responsabilidade social não escapam às contradições. Não se vai aqui esgotar esse assunto; longe disso. Mais importante que tentar, inutilmente, resolver algumas controvérsias é incomodar certezas autorreferentes.

Primeira observação, óbvia, mas necessária: responsabilidade social da Universidade não é a mesma coisa que responsabilidade da sociedade em relação à Universidade. Esta última assume, sem declarar, que a Universidade (por extensão, a educação) é um patrimônio público a ser mantido e desenvolvido por todos. Todo princípio tem o dever como contrapartida. O princípio é: a educação (portanto, a Universidade) é um bem público, essencial e insubstituível, patrimônio comum, direito de todos. O dever é: a sociedade (e, por óbvio, o Estado) é responsável pela manutenção, funcionamento, supervisão e democratização desse patrimônio público, sempre com a mais elevada qualidade possível. Qualidade técnica e, inafastavelmente, social. A qualidade universitária deve ser para todos e em benefício de todos. Não sendo para todos, não é qualidade social. A sociedade constrói a Universidade e a Universidade constrói a sociedade, guardados os respectivos limites e limitações.

Já a responsabilidade social da Universidade remete à questão dos fins. A esse respeito também proliferam múltiplas visões. É amplamente disseminado o ponto de vista de que a Universidade tem como fim, ou finalidade, a formação. Mas o que é mesmo a formação? A 
ideologia hegemônica invadiu instituições e poderosas organizações globais e se tornou a verdade natural e pouco questionada para comunidades e toda a gente. Pouco se cultuam os valores fundamentais da existência humana, muito se cuida de preços e lucros. O social está sendo naturalmente engolido pelo mercado. Para os cegados pelo mercado, formação é capacitação técnica e profissional em função do enriquecimento de empresas e seus grupos de interesse. Nessa perspectiva, o papel da Universidade, sua obrigação e finalidade principais, é preparar mão-de-obra técnica e profissionalmente capacitada e atualizada para a sustentação e desenvolvimento da economia de mercado. Cidadão, cidadania, bem social, nada disso importa nessa lógica. A Universidade deveria, então, ensinar e pesquisar técnicas e conhecimentos úteis ao sistema econômico prevalente.

Indiscutível que a Universidade tem o dever de formar profissionais competentes e comprometer-se com o desenvolvimento econômico do país. Mas capacitação técnica é apenas uma parte. A vida é muito mais que isso. Técnica sem ética e ciência sem consciência podem produzir mais barbárie que civilização, mais destruição e mortandade que construção da liberdade e da dignidade da vida. Os criadores de bombas e armas de morticínio em larga escala eram ou são cientistas renomados, possuidores dos mais espetaculares conhecimentos e técnicas e disputados a preço de ouro no sistema bélico. Importantes economistas sem ética e senso cidadão muitas vezes favorecem a ampliação de nefastas desigualdades e produção de pobreza e fome, em favor dos donos do mundo. Não há nada mais execrável que a fome. Terrível é sofrer a fome. Lamentavelmente, abaixo da linha da pobreza ou em situação de miséria absoluta, são bilhões de indivíduos espalhados pelo mundo. Deveria ser chocante pensar que, para superar a fome a miséria do mundo, bastaria uma pequeníssima parte dos recursos que se gastam em armamentos e na mortandade programada. A miséria absoluta de grande parte da humanidade é fabricada pelo sistema vigente de desigualdade e injustiça social. Para desenvolver a indústria bélica é necessário produzir inimigos. Sem inimigos, não haveria guerra. Disso tratam os líderes dos países mais poderosos. Fabricam inimigos para justificar a necessidade de armas de destruição. O setor de armamentos é provavelmente o único a não sofrer crises. A miséria e a fome produzem mais violência, e para combater a violência é preciso fabricar mais armas, cada vez mais tecnologicamente sofisticadas e caras. "A matança em massa se tornou o feito máximo da civilização" (2004, p. 84), diz Galbraith.

Todos os líderes desses e de outros importantes setores foram, em sua maioria, formados nas melhores instituições do mundo. Do ponto de vista de sua capacidade intelectual merecem muito respeito e reconhecimento. Atingem o grau dito de excelência. As Universidades têm grande mérito relativamente a esses cientistas e técnicos, grandiosa participação no espetacular avanço da ciência e da tecnologia, mas não podem fazer de contas de que não são responsáveis por alguns descaminhos da civilização. Se negligenciam a 
formação de pessoas éticas e socialmente solidárias, se privilegiam quase exclusivamente a capacitação técnica de mão de obra, se aderirem cegamente à lógica e aos ideais do mercado, então, estarão contribuindo para o fortalecimento do sistema de desigualdades e iniquidades, de guetos sociais, de rupturas de valores de família, de individualismos e desconstrução da alteridade. Aderindo cegamente ao mercado, por exclusão da sociedade solidária e democrática, estarão contribuindo para a produção da fome, violências e ódios. Onde a fome e as injustiças prevalecem, vige uma sociedade violenta e odienta.

Graças ao trabalho dos pesquisadores universitários e congêneres, a produção de alimentos avançou muito nos últimos anos, proporcionou enormes ganhos a grandes corporações nacionais e internacionais, mas não são muitos os alimentos que chegam à mesa dos mais pobres. É chocante saber que uns pouquíssimos multibilionários detêm mais riquezas e poder que a grande maioria da população mundial. Uns morrem de fome, outros adoecem de muito comer. Nem sempre os laboratórios da área da saúde têm como prioridade a fabricação de remédios para o povo. O lucro é o deus a ser reverenciado. Ensina Milton Santos (2.000, p. 72): "a pobreza é politicamente produzida pelos atores globais com a colaboração consciente dos governos nacionais [...] com a conivência dos intelectuais contratados - ou apenas contatados - para naturalizar essa naturalização". Mas há alternativas: "não há apenas um caminho e este não é obrigatoriamente o da passividade" (2000, p. 78).

Não se quer dizer aqui que as mazelas do mundo se devem às Universidades, mesmo porque elas não são blocos homogêneos e uniformes. Mas não se deve deixar de questionar o lugar e os papeis que têm no mundo atual. O que está em questão é a formação. São os seus sentidos e usos. E com isso, pensar no lugar da Universidade no sistema global e na vida comum dos indivíduos. Como bem público, a Universidade deve contribuir para o desenvolvimento econômico, mas com justiça social. Deve produzir conhecimentos científicos e tecnológicos, mas nunca negligenciar o interesse social. Deve ser democrática e formar cidadãos com elevados valores da democracia. Deve ser universal, mas respeitando a cultura plural e as diferenças sociais e axiológicas dos diversos indivíduos e cidadãos. Deve se inserir produtivamente na globalização, mas não em detrimento dos valores da soberania nacional. Deve ser includente, acolher a todos que possuam requisitos adequados, colaborar no atendimento de algumas das necessidades básicas da população em geral, sobretudo dos mais carentes, em educação, saúde, serviços, esportes, lazer, movimentos sociais voltados ao fortalecimento dos direitos humanos etc. Deve formar pessoas conscientes, cultas e produtivas para a cidadania e o aprofundamento da democracia. É pela educação fundada em valores e princípios fundamentais que se pode evitar, ao menos em parte, que a mortandade, a fome, a injustiça e o ódio prevaleçam como se fossem o natural comportamento humano. Universidade não deve formar indivíduos para serem mais competitivos, mas, sobretudo, para 
serem cidadãos solidários, éticos, intelectual e profissionalmente capacitados. É justo e bom reconhecer que as Universidades públicas brasileiras, ainda que não homogeneamente, têm cumprido um papel relevante para a sociedade, nas mais diversas áreas e setores da vida. A relação é longa, mas cabe lembrar alguns exemplos reais do cumprimento da responsabilidade social. São trabalhos em hospitais do sistema público, em escolas e organizações culturais, em atividades de caráter político, em programas de inclusão em benefício de indivíduos normalmente desfavorecidos, pesquisa de alta complexidade e atualidade, destacadamente na saúde e na produção de alimentos, comprometimento com a educação e a sustentabilidade ambiental, desenvolvimento do complexo ciência-tecnologia-inovação etc. Nenhuma outra instituição pública tem tanto e tão relevante comprometimento com os interesses sociais e nacionais. Países e sociedades sem universidades públicas socialmente responsáveis e comprometidas se condenam ao atraso, à ignorância e à cegueira do povo.

O que se está ponto em foco é, pois, a formação humana, plenamente, não apenas em seu viés economicista, competitivista e tecnicista. Isso põe em questão os fins, o lugar e os modos de funcionamento da Universidade no mundo atual. Formar que tipo de cidadão, ensinar para qual sociedade e para qual futuro? Isso impõe à práxis educativa adotar a crítica de suas concepções naturalizadas e, "através de alterações em sua autoimagem e em sua configuração política, introduzir freios e contrapesos no 'desgoverno' do avanço científicotecnológico, atualmente em desabalada e explosiva carreira” (BECK, 2011, p. 273).

Por que trazer esse tema tão controverso e central para esta revista? Porque uma revista deve atuar como uma espécie de intelectual coletivo. Não se trata de fixar consensos e petrificar supostas verdades. Deve ser um espaço de estudos e diálogos, uma rede de interlocução aberta a controvérsias e questionamentos. Um instrumento de provocação e apelo às reflexões. A responsabilidade social deve ter enorme centralidade no sistema universitário. Deveria estar no centro das avaliações da Universidade.

\section{Referências}

BECK, Ulrich. Sociedade de risco: rumo a uma outra modernidade. $2^{\mathrm{a}}$ edição. São Paulo: Editora 34, 2011.

GALBRAITH, John Kenneth. A economia das fraudes inocentes: verdades para o nosso tempo. São Paulo: Companhia das Letras, 2004.

SANTOS, Milton. Por uma outra globalização: do pensamento único à consciência universal. Rio de Janeiro: Record. 2000. 